\section{What lingua franca?}

SIR - In your coverage of "Science in Japan" you refer to the Japanese language as a barrier to "Japan's full participation in international science". I believe that this represents only a Western view. In terms of the total number of native speakers of a language, English comes a distant second to Chinese. In Asia alone, native speakers of Chinese live in China, Taiwan, Thailand, Hongkong, Malaysia and Singapore. Most foreign students studying in Japan are also natives of these countries, as is also the case in Korea. Furthermore, the Japanese language boom is also seen predominantly in these countries. Because of the cultural relationships of the Chinese and Japanese languages, ethnic Chinese students find it easier to learn Japanese than English.

To identify a simplified universal language of science and communication, Margaret Mead noted that "there might be a written language to permit the visual representation of ideas, independent of existing languages, rather like the relationship of Chinese script with the various spoken languages of China" ${ }^{2}$. How the Japanese language fits this description can be deduced as follows: (1) the Chinese use approximately 5,000 kanji ideograms; (2) the Japanese have reduced the kanji ideograms from 5,000 to nearly 2,000 for their daily use; (3) according to Daub et $a l^{3}$, a foreigner can comprehend 90 per cent of the technical literature in Japanese if he or she can recognize 500-600 kanji ideograms.

For students whose native tongues are Chinese and Korean, this simplicity makes the Japanese language a useful tool to learn science.

\section{Sachi Sri Kantha}

Department of Enzymes \& Metabolism, Osaka BioScience Institute,

6-2-4 Furuedai, Suita,

Osaka 565, Japan

1. Nature 359, 573-582 (1992)

2. New Scientist 23 December 1971, 225.

3. Daub, E. E., Bird, R. B. \& Inoue, N. Comprehending Technical Japanese (University of Tokyo Press, 1975).

SIR - There is a general trend to adopt English as a lingua franca in scientific communication. The director of the Library of Geological Sciences of the University of Barcelona, $\mathrm{Mr}$ Jordi Casadellà, and I are trying to analyse the actual situation of English as a lingua franca in geological sciences. To this end we have taken a sample of the recent geological journals and books to see how fast English is becoming the exclusive, or at least the main, language used in geological publications. In Western European countries in which the language of the people is not English, the

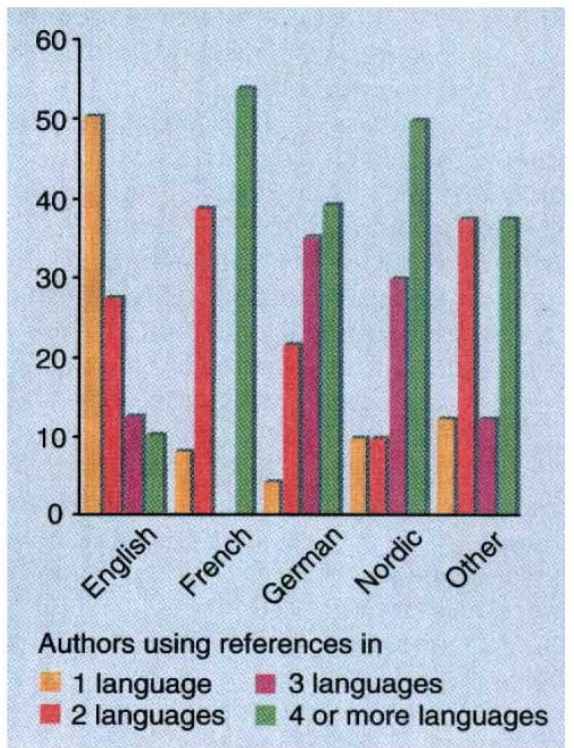

geological papers in reputable scientific journals are not predominantly English. At the same time, most English-speaking scientists tend almost exclusively to cite English-written scientific literature. This is a serious problem because it seems evident that a full appreciation of the breadth of geological knowledge makes necessary a knowledge of the scientific production of Western European countries, written mainly in French and German but also in Spanish and Italian and other languages. In geological sciences, the evidence that an author does not read languages other than English is a sign that his information is significantly incomplete.

\section{Salvador Reguant}

Universitat de Barcelona,

Facultat de Geologia,

Zona Universitaria de Pedralbes,

08071 Barcelona, Spain

\section{Consciousness in other words}

SIR - Despite the belief that linguistic confusion over the meaning of consciousness no longer forms a barrier to scientific investigation ${ }^{1}$, further correspondence and reviews in Nature ${ }^{2-4}$ suggest that the definition of consciousness is still disturbing. I suggest that 'consciousness' is a term that is useful in everyday speech, but is confusing as a subject of serious study because the word is shorthand for a parcel of ideas.

One sense of the term 'conscious' is simple and uncrontroversial: it is applicable to other individuals to mean that they are responding in a complex, nonreflex manner to stimuli. In this sense the word is used without embarrassment of any animal whose reactions to stimuli we can interpret by comparison with our own; even etherized flies can be described as regaining consciousness. In this meaning, 'consciousness' can be replaced by 'responsiveness'.

In its other meanings, a scientific approach is impeded by the perception that consciousness is detectable only as personal experience, and can be inferred in others only by acceptance of their reports of it. This being so, evidence for consciousness in others depends on human communication, and there is no way in which we can decide, except by supposition, whether the phenomenon exists in the absence of speech $^{4}$. The persistence of the debate about its existence in animals also implies that we are unable to predict simple evidence for consciousness: it has no clear consequences for animal behaviour.

Even within this second type of meaning, I suggest that there are two ideas. One is that consciousness comprises the set of thoughts and sensations at any current moment; these are the internal counterpart of reactivity, and are by definition unavailable, except by report, to an outside investigator. Nevertheless, correlation of such reports with measurements of neural activity are a fruitful means of investigating the nature of sensation and ratiocination.

The second intrapersonal meaning of 'consciousness' is more complex; it is usually employed in the past tense and relates consciousness to memory ${ }^{3}$, for example in the remark "I was conscious of that event". This statement can be replaced by "I can now remember that event"; conversely, if I say I was unconscious of an event, all I can legitimately state is that I cannot now recall it. Here consciousness is a projection into the past of the current experience of memory recall, giving a description of a supposed state of mind when the memory was laid down. It may be embarrassment at the fallibility of human memory that makes us prefer the more positive declaration "I was not then laying down memories" to "I cannot now remember". Whether this is the case or not, it seems to me that this meaning of the word is essential to our understanding of the phenomenon of consciousness: since these are internal mental activities, only those that leave a record in memory have a continued existence and can become the basis of that experience which defines individuality.

\section{John Clutterbuck}

Department of Genetics,

Glasgow University,

Glasgow G11 5JS,

1. Gray, J. Nature 358, 277 (1992)

2. Fletcher, H. L. Nature $\mathbf{3 5 9}, 665$ (1992)

3. Longuet-Higgins, C. Nature 360, 117 (1992)

4. Whiten, A. Nature 360, 118 (1992) 